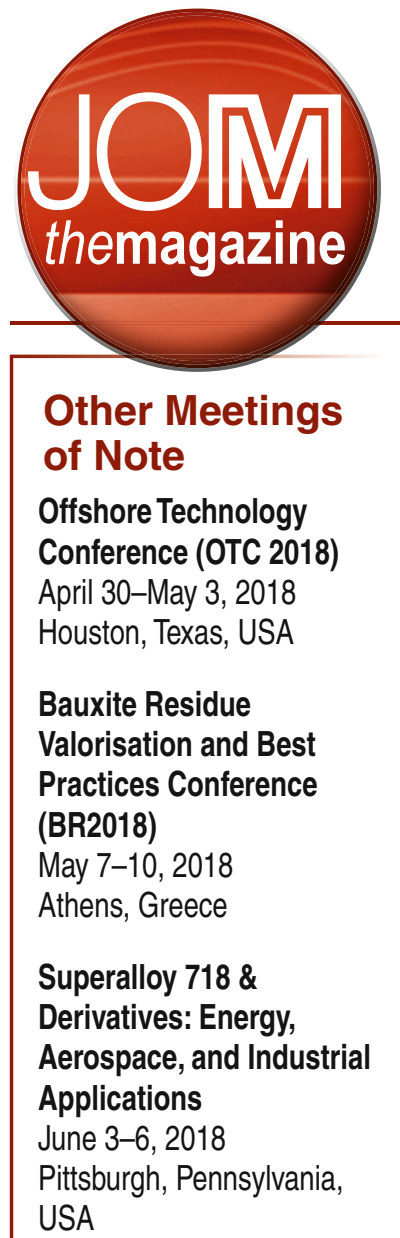

18th International

Conference on the

Strength of Materials

(ICSMA 18)

July 15-19, 2018

Columbus, Ohio, USA

Diversity in the Minerals, Metals, and Materials

Professions (DMMM3)

July 23-24, 2018

Santa Barbara, California, USA

\section{Extraction 2018}

August 26-29, 2018

Ottawa, Canada

Materials Science \&

Technology (MS\&T18)

October 14-18, 2018

Columbus, Ohio, USA

TMS 2019 Annual Meeting \& Exhibition (TMS2019) March 10-14, 2019 San Antonio, Texas, USA

\title{
TMS meeting headlines
}

View all upcoming meetings online at www.tms.org/Meetings.

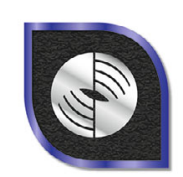

CONTROL OF

POTLINE SCRUBBER

\& FUGITIVE EMISSIONS

for Aluminum Smelters Course

May 21-24, 2018

Hilton Québec

Québec City, Québec, Canada

Discount Registration Deadline:

March 21, 2018

www.tms.org/PSFE2018

- Returning for the third year in a row, this program is solely focused on providing a complete, intensive overview of the latest techniques, as well as the fundamental knowledge necessary for effectively managing and reducing emissions in aluminum smelting.

- Be sure to register on or before the discount deadline of March 21, 2018, to save $\$ 100$ on registration fees.

The 4th International Congress on

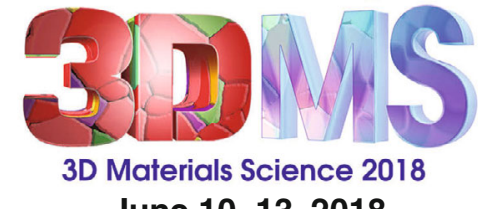

June 10-13, 2018

Kulturværftet (Culture Yard) Conference Center

Helsingør (Elsinore), Denmark

Discount Registration Deadline: May 8, 2018

www.tms.org/3DMS2018

- Confirmed keynote speakers for the 4th International Congress on 3D Materials Science (3DMS 2018) include: Tresa Pollock, University of California, Santa Barbara; Henry Proudhon, Mines Paristech, Centre des Matériaux; and Stephane Roux, National Center for Scientific Research. Visit the congress website for technical topics and more program information.

- Enjoy a more complete meeting experience when you stay at the Beach Hotel Marienlyst, the official hotel of 3DMS 2018. Book your room at the attendee rate by May 8, 2018.

\section{ADDITIVE MANUFACTURING BENCHMARKS \\ BENCH2O18
June 18-21, 2018}

National Institute of Standards and Technology (NIST) Headquarters Gaithersburg, Maryland, USA

Benchmark Modeling Submission

Deadline: May 18, 2018

www.tms.org/AMBench2018

- The Additive Manufacturing

Benchmarks 2018 (AM-Bench 2018) call for benchmark test entries is open through May 18, 2018. For detailed descriptions of benchmark tests, descriptions of modeling challenges, and directions for submitting simulation results, visit the NIST Benchmark Tests website: www.nist.gov/ambench

- AM-Bench 2018 will provide a venue where modelers and experimentalists can come together to discuss what works and to identify strategies for resolving what doesn't work.

TNG > TMS METALLURGICAL AND MATERIALS PROFESSIONAL ENGINEER (PE) LICENSING EXAM REVIEW COURSE

August 1-4, 2018

Kimpton Hotel Monaco Pittsburgh Pittsburgh, Pennsylvania, USA

Discount Registration Deadline: June 4, 2018 www.tms.org/PEReview2018

- Make your plans to attend by June 4, 2018, and register for this course at the discounted rate.

- The small class size and group work sessions during this program will help you prepare for the Metallurgical and Materials Engineer PE Licensing Exam.

- Course instructors include: Charles V. White, PE, Kettering UNiversity; Indrajit Charit, PE, University of Idaho; Dana Medlin, PE, EAG Laboratores and South Dakota School of Mines and Technology; Erik Mueller, PE; and Steven R. Sopher, JSP. 